\title{
Effect of Priming Principle on Propofol Dose Required to Induce General Anesthesia
}

Hafiz Muhammad Hamid, Sarmad Masud, Aamir Waseem, Aamir Bashir, Asma Samreen, Saima Ashraf

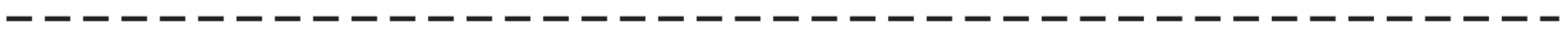

ABSTRACT:

Objective: To compare the mean induction dose of Propofol to induce general anesthesia by conventional method versus mean induction dose after applying priming principle.

Study Design and Setting: Randomized controlled trial at Operation theatre complex, Shalamar Hospital, Lahore from November 2016 to May 2017.

Methods: A total of 100 patients aged 18-55 years were equally divided into control and study groups. After standard anesthetic monitoring, intravenous propofol was used for induction of general anesthesia by conventional method in Control (C) group and by applying Priming principle in Study (S) group. Total dose requirement of propofol was noted. Data was analyzed in SPSS version 20 and paired sample t-test was applied. P-value of < 0.05 was considered as significant.

Results: The mean induction dose of propofol was $70.90 \pm 16.77 \mathrm{mg}$ in study group (S) as compared to $94.60 \pm 20.22$ $\mathrm{mg}$ in the control group (C). The difference of mean induction dose in both groups was $23.7 \pm 3.45 \mathrm{mg}$ and thus $\mathrm{p}$-value of 0.000 .

Conclusion: There was significant reduction of dose of propofol required to induce general anesthesia in elective surgical patient by applying priming principle.

Keywords: General anesthesia, Priming principle, Propofol.

\section{INTRODUCTION:}

We are living in the era of day care surgery and anesthesia. Unusual and prolong hospital stay due to anesthetic drugs definitely increases economic burden and risk of hospital acquired complications. Propofol is the most commonly used intravenous anesthetic induction agent used due to its property of smooth and more rapid induction, rapid awakening, clear headed recovery, decreased incidence of post-operative nausea and vomiting, better intubating conditions and upper airway integrity compared to thiopentone. ${ }^{1,2}$ However, the single bolus induction dose of

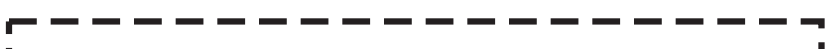

I Hafiz Muhammad Hamid

I Post-graduate resident Anesthesia

Shalamar Medical \& Dental College, Lahore

IEmail: aimc65@gmail.com

Sarmad Masud

I Associate Professor Anesthesia

I Shalamar Medical \& Dental College, Lahore

I Aamir Waseem

Assistant Professor Anesthesia

Shalamar Medical \& Dental College, Lahore

I Aamir Bashir

Assistant Professor Anesthesia

I Shalamar Medical \& Dental College, Lahore

I Asma Samreen

I Post-graduate Resident Anesthesia

I Shalamar Medical \& Dental College, Lahore

I Saima Ashraf

Post-graduate resident Anesthesia

Shalamar Medical \& Dental College, Lahore

Received: 03-10-2019

Accepted:12-12-2019

I

JBUMDC 2020;10(1):40-43
Propofol causes profound hemodynamic instability due to direct myocardial depressant and decreased systemic vascular resistance. . $^{2,3}$

Muhammad and colleagues found that single bolus dose of $2 \mathrm{mg} / \mathrm{kg}$ resulted in the decrease of $26-28 \%$ of systolic blood pressure, $19 \%$ of diastolic blood pressure and $11 \%$ of mean arterial pressures. ${ }^{4}$ The literature review reveals that various techniques can be used to reduce the induction dose requirements of propofol i.e. concurrent use of nitrous oxide, opioids, barbiturates like thiopentone, benzodiazepines like midazolam, augmentation with local anesthetics or magnesium sulfate and use of "Priming Principle".,9 Priming Principle! has been successfully used to reduce the conventional dose of non-depolarizing muscle relaxants for early achievement of intubating condition. .,13,14 $^{2}$

Priming principle has been successfully practiced to reduce the total induction dose of Propofol in different studies. Sanket et al used Midazolam and Fentanyl with propofol as priming agents in their study. They found a statistically significant $(p<0.05) 27.69 \%$ reduction in induction dose requirement in study group after applying Priming principle. ${ }^{1}$ Number of techniques have been tried to counteract the hypotensive effects of propofol i.e. slow administration of drug, preloading, and administration of vasoactive agent (phenylephrine) to raise blood pressure. ${ }^{4,13}$ However; Priming principle has not been studied on induction dose of propofol among local population in Pakistan and indeed it was the rationale of the study.This study was designed to determine the effects of priming principle on total dose requirement of propofol for induction of general anesthesia to reduce the dose of propofol. Therefore this study was aimed to compare 
the mean induction dose of Propofol to induce general anesthesia by conventional method versus mean induction dose after applying priming principle.

\section{METHODOLOGY:}

This randomized control trial was conducted at operation theatre complex, Shalamar Hospital, Lahore form November 2016 to May 2017.Non-probability consecutive sampling technique was used to calculate the sample size of 100 patients with $95 \%$ confidence level and $80 \%$ power of test.

Following approval from our IRC; 100 patients of age 1855 years with American Society of Anesthesiologists (ASA) physical status I \& II were included. These patients were scheduled for elective surgery under general anesthesia i.e. cholecystectomy, umbilical hernia repair, incision and drainage, thyroidectomy, EUA (examination under anesthesia), arthroscopy, corrected surgery for upper limb fractures, tonsillectomy \& septoplasty. Patients refusing the consent to participate, patients with history of allergy to opioid and egg, anticipated difficult airway (Mallampati class III \& IV), pregnant and lactating mothers were excluded from the study. Informed consent was taken from each patient, ensuring confidentiality and no risk involved to the participants. Patients were equally divided into control (C) and study (S) groups by lottery method. After transferring the patient to the operation theatre, intravenous line was secured and standard anesthetic monitoring was attached. Propofol and plain Lidocaine were mixed to decrease the chances of pain on injection. ${ }^{5}$ Midazolam $0.03 \mathrm{mg} / \mathrm{kg}$ and nalbuphine $0.1 \mathrm{mg} / \mathrm{kg}$ were given intravenously over 30 seconds. This was followed by administration of propofol by conventional single bolus dose of $2 \mathrm{mg} / \mathrm{kg}$ in Control (C) group. Priming Principle was used in study (S) group; $20 \%$ of the calculated dose of $2 \mathrm{mg} / \mathrm{kg}$ was administered initially and remaining propofol was given after 30 seconds till the loss of eyelash reflex. Total dose requirement of Propofol until the loss of eyelash reflex was noted. This was followed by muscle relaxant to facilitate the tracheal intubation.

INDUCTION DOSES OF PROPOFOL: Conventional method: Conventional single bolus dose of propofol $(2 \mathrm{mg} / \mathrm{kg})$ was given for the induction of anaesthesia.

Priming principle: Initially, 20\% of calculated Propofol dose $(2 \mathrm{mg} / \mathrm{kg})$ was given as priming agent followed by 30 seconds interval. Remaining propofol was administered till the loss of eyelash reflex.
Data was entered and analyzed by SPSS version 20 p-value $<0.05$ was considered statistically significant. Quantitative variables such as age, weight BMI and required dose of propofol in both groups were presented as mean and standard deviation. Gender and ASA physical status was presented as frequency and percentages. The independent sample ttest was used to compare the outcome variables i.e. mean induction dose of Propofol.

\section{RESULTS:}

Among Control Group (C): The mean age w a s 36.46 \pm 11.59 years with range of 18 years to 55 years. Out of 50 patients, $20(40 \%)$ were male and $30(60 \%)$ were female. Mean weight was $66.74 \pm 15.11 \mathrm{~kg}$ and BMI was $28.42 \pm 4.99 \mathrm{~kg} / \mathrm{m}^{2} .38$ patients $(76 \%)$ were ASA I and (24\%) were ASA II. Mean induction dose of propofol was $94.60- \pm 20.22 \mathrm{mg}$. (Table I)

Study Group (S): Mean age was $33.88 \pm 11.05$ years with range of 18 years to 54 years. Out of total 50 patients, $23(46 \%)$ were male and 27 (54\%) were female. Mean weight was $68.28 \pm 14.42 \mathrm{~kg}$ and BMI was $28.22 \pm$ $5.15 \mathrm{~kg} / \mathrm{m}^{2} .39(78 \%)$ patients were ASA I and (22\%) were ASA II. Mean induction dose of propofol was $70.90 \pm 16.77 \mathrm{mg}$. (Table II)

Using unpaired t-test, the difference of mean induction dose in both groups was $23.7 \pm 3.45 \mathrm{mg} \&$ p-value 0.000 showed statistically significant results (Table III).

Table I: Mean induction dose of propofol (mg) by conventional method:

\begin{tabular}{|l|l|c|}
\hline \multirow{4}{*}{$\begin{array}{l}\text { Mean induction dose } \\
\text { of Propofol (mg) }\end{array}$} & Number of patients & 50 \\
\cline { 2 - 3 } & Minimum dose & 60 \\
\cline { 2 - 3 } & Maximum dose & 150 \\
\cline { 2 - 3 } & Mean & 94.60 \\
\cline { 2 - 3 } & Std. Deviation & 20.224 \\
\hline
\end{tabular}

Table II: Mean induction dose of propofol (mg) after applying priming principle

\begin{tabular}{|c|l|c|}
\hline \multirow{4}{*}{$\begin{array}{c}\text { Mean induction dose of } \\
\text { Propofol (mg) }\end{array}$} & Number of patients & 50 \\
\cline { 2 - 3 } & Minimum & 21 \\
\cline { 2 - 3 } & Maximum & 39 \\
\cline { 2 - 3 } & Mean & 70.90 \\
\cline { 2 - 3 } & Std. Deviation & 16.772 \\
\hline
\end{tabular}

Table III: Unpaired t-test for Dose of propofol:

\begin{tabular}{|c|c|c|c|c|c|c|}
\hline \multirow{3}{*}{ Dose (mg) } & Group & Number of patients & Mean & Standard Deviation & Standard Errorof Mean & P-Value \\
\cline { 2 - 6 } & Control & 50 & 70.90 & 16.772 & 2.372 & \multirow{2}{*}{0.000} \\
\cline { 2 - 6 } & Study & 50 & 94.60 & 20.224 & 2.860 & \\
\hline
\end{tabular}




\section{DISCUSSION:}

Anesthesia induction is the most important and eventful phase during the entire course of general anesthesia. Propofol, a phenol derivative is commonly used for induction of anaesthesia and procedural sedative agent for emergent procedures. ${ }^{9}$ Due to its rapid onset, short duration of action and suppression of airway reflexes, propofol has acquired the most preferred choice for induction of anaesthesia. ${ }^{10}$ However, the hemodynamic instability and pain on injection caused by the conventional induction dose of $2-3 \mathrm{mg} / \mathrm{kg}$ is the major concern for the anesthesiologist. ${ }^{6,10,20}$

Multiple strategies and methods have been adopted in an effort to reduce the induction dose requirements of propofol. 9,13 The technique of priming principle involves the use of smaller doses of the priming agent before the use of single bolus dose. The application of this priming technique to the use of propofol either as an induction agent or as an infusion for ICU sedation has distinct advantages. ${ }^{16,17}$ There is a decrease in total dose of propofol required for induction as well as pain on injection appears to diminish considerably ${ }^{18}$. The hemodynamic changes are also less pronounced. ${ }^{20}$

In the present study we have tried to evaluate whether priming principle applied to the induction dose of propofol reduces the total dose requirement in our population.

The mean induction dose required in the priming group was significantly lower $70.90 \pm 16.77 \mathrm{mg}$ than in the control group $94.60 \pm 20.22 \mathrm{mg}$. There was a significant difference $23.7 \pm 3.45 \mathrm{mg}$ of mean induction dose of propofol in both groups.

Our study results were different from a previous study ${ }^{1}$ in which mean induction dose of propofol in control group (C) was $94.60 \pm 20.22 \mathrm{mg}$ as compared to $113.27 \pm 18.68 \mathrm{mg}$ while $70.90 \pm 16.77 \mathrm{mg}$ as compared to $81.37 \pm 15.82 \mathrm{mg}$ in study group $(\mathrm{S})$. The reduction of propofol dose in our study was $27 \%$ as compared to $25 \%$ in other study.

Thus, we found that propofol priming principle technique attains comparable anesthetic depth of anesthesia with a significantly lower dose when compared to the conventional, single bolus dose of propofol during induction.

However, few limitations of the study included; single center trial only covering ASA I \& II, non-pregnant and elective patients. The use of an invasive arterial blood pressure monitoring could have revealed more specific results.

There is room for large multicenter trials and different population of patients to determine the important role of this priming principle. Further avenues of research include use of propofol priming technique impacting the pain on injection and incidence of postoperative nausea \& vomiting.

\section{CONCLUSION:}

The induction dose requirement of propofol is significantly lower in the priming principle group when compared to the conventional induction group in elective surgical patients

\section{REFERENCES:}

1. Sanket H, Mehta, Pinalben G, Dabhi, Golwala, Upadhyay. Effect of Priming Principle on the induction dose Requirement of Propofol. Int J Res Med. 2015; 4(1): 69-73.

2. Paul F, White, Matthew RE. Intravenous Anesthetics. In:Barash PG,Paul GB,Bruce FC,Robert KS,Michael KC,Christine S, editors. Clinical Anesthesia, 7th ed. Philadelphia: Lippincott Williams \& Wilkins; 2013: 487.

3. Anil KA, Sanikop CS, Kotur PF. Effect of Priming Principle on the induction dose requirements of Propofol - a randomized clinical trial. IJA 2006; 50:283-87

4. Muhammad I, Fazal HK, Mansoor AK. Attenuation of Hypotension using Phenylephrine during induction of anesthesia with propofol. JPMA 2007; 57(11):543-47

5. Jalota L, Kalira V, George E, Shi Y-Y, Hornuss C, Radke $\mathrm{O}$, et al. Prevention of pain from Propofol injection: systematic review and meta-analysis. BMJ. 2011;342:1110-5

6. Gan TJ. Pharmacokinetic and pharmacodynamic characteristics of medications used for moderate sedation. Clin Pharmacokinet 2006; 45:855-9.

7. McKeating K, Bali IM, Dundee JW. The effects of thiopentone and propofol on upper airway integrity. Anaesthesia1988;43:638-40.

8. Kumar A, Sanikop CS, Kotur PF. The effect of priming principle on induction dose requirements of propofol. Indian J Anaesth 2006;50:283-7

9. Firouzian A, Emadi SA, Baradari AG, Mousavi R, Kiasari AZ. Can low dose of propofol effectively suppress fentanylinduced cough during induction of anaesthesia? A double blind randomized controlled trial. J Anaesthesiol Clin Pharmacol 2015;31:522-5.

10. Miner JR, Burton JH. Clinical practice advisory: Emergency department procedural sedation with propofol. Ann Emerg Med 2007; 50:182-8.

11. Fairfield, Dritsas A, Beae RJ. Hemodynamic effects of propofol: induction with $2.5 \mathrm{mg} \mathrm{kg}-1$. Br J Anaesth. 1991; 67:618-20.

12. Green SM, Krauss B. Barriers to propofol use in emergency medicine. Ann Emerg Med 2008; 52:392-8.

13. Amatya, A Marhatta, M Shrestha, Gentle \& Shrestha, Anil. A Comparison of Midazolam Co-induction with Propofol Priming in Propofol Induced Anesthesia.. Journal of Nepal Health Research Council. 2014;12:44-48.

14. Karlo R, Singh NR, Singh KM, Singh TH, Devi NA, Devi MB. Priming effects of propofol during induction of anesthesia. J Med Soc 2015;29:92-5.

15. S. K. Gvalani1, Suresh D, Bhodane. Effect of priming principle on the induction dose requirements of propofol in patients undergoing elective surgeries under general anaesthesia. Int J Res Med Sci. 2016;9:3824-3828.

16. Prathapadas U, Gomathiamma M, Arulvelan A, Lionel KR, Hrishi AP. A study comparing propofol auto-coinduction and standard propofol induction in patients undergoing general anesthesia without midazolam pretreatment: A prospective randomized control trial. Anesth Essays Res 2018;12:690-4.

17. Biswal, P., Singh, S. and Taank, P. 2018. Application of Priming Principle on the induction dose requirements of propofol - A Randomized Clinical Trial. International Journal of Biomedical Research. 2018;9:320-324. 
Hafiz Muhammad Hamid, Sarmad Masud, Aamir Waseem, Aamir Bashir, Asma Samreen, Saima Ashraf

18. Devendra W. Thakare,Urvi H.Desai, Kailash S. Sharma. Evaluation of efficacy of priming dose of propofol in reducing induction dose requirements in patients undergoing elective surgeries under general anaesthesia. Int J Res Med Sci. 2016;49:3717-3723

19. Vikram Singh Rathore,Shalendra Singh, Priya Taank,Ankur Khandelwal. Clinical Analysis of Propofol, Etomidate and an Admixture of Etomidate and Propofol for Induction of General Anaesthesia. Turk J Anaesthesiol Reanim. 2019 Oct; 47: 382-386.
20. Shrasti Tambake Pratap, Shareena T, Syed Fazal Mahmood, S. Padmanabha. Hemodynamic Study during Induction of General Anaesthesia with Propofol Using Priming Principle. Journal of Evolution of Medical and Dental Sciences 2015; 4: 10914-10920.

21. Jyothi Mallikarjuna, Purneema K. Co Induction: A Comparative Study of Midazolam Ketamine and Propofol as Coinducing Agents to Propofol. Journal of Evolution of Medical and Dental Sciences 2015; 4(61):10666-10680 